\title{
PENERAPAN METODE DENAVIT-HARTENBERG PADA PERHITUNGAN INVERSE KINEMATICS GERAKAN LENGAN ROBOT
}

\author{
Agus Budi Dharmawan ${ }^{1}$, Lina $^{2}$ \\ Teknik Informatika, Fakultas Teknologi Informasi, Universitas Tarumanagara \\ agusd@fti.untar.ac.id
}

\begin{abstract}
ABSTRAK
Metode Denavit-Hartenberg merupakan metode yang menggabungkan proses perhitungan rotasi dan translasi menjadi sebuah matriks yang menyertakan nilai-nilai sudut putar dan jarak sendi dari sebuah lengan robot. Dalam beberapa aplikasi, metode Denavit-Hartenberg umumnya digunakan dalam perhitungan Forward Kinematics. Dalam penelitian ini dirancang aplikasi yang menggunakan metode Denavit-Hartenberg untuk menghitung sudutsudut tiap sendi pada Invers Kinematics untuk menggerakan sebuah lengan robot. Matrik Denavit-Hartenberg yang berisi perhitungan rotasi dan translasi digunakan untuk mendapatkan nilai-nilai sudut untuk menggerakkan tiap motor sendi. Setiap Matriks akan mewakili setiap titik frame pada platform lengan robot. Hasil keluaran dari frame yang dicari akan menghasilkan sudut-sudut tiap joint yang akan digunakan untuk menggerakan lengan robot.
\end{abstract}

Kata Kunci: Denavit-Hartenberg, Invers Kinematics, Lengan Robot

\section{PENDAHULUAN}

Lengan Robot digunakan untuk membantu manusia melakukan beberapa tugas seperti memilih dan menempatkan suatu objek. Konsep gerakan Lengan Robot diadaptasi dari hasil pengamatan gerakan dengan meniru gerakan lengan manusia. Lengan robot mempunyai dua gerakan pada pergerakan link, yaitu revolute joint (sendi putar) dan prismatic joint (sendi geser).

Lengan Robot juga banyak digunakan untuk berbagai keperluan dalam meningkatkan produksi, memiliki bentuk lengan-lengan kaku yang terhubung secara seri dan memiliki sendi yang dapat bergerak memanjang/memendek (translation) maupun gerakan berputar (rotation). Robot lengan memiliki bentuk meniru struktur tangan manusia dan satu sisi lengan yang disebut pangkal lengan ditanam pada suatu bidang atau area yang statis, sedangkan sisi lain yang disebut sebagai ujung lengan (end of effector) dapat bergerak bebas menuju area yang diinginkan. Pada bagian ujung lengan robot dapat dipasang berbagai perangkat tambahan seperti kamera, sensor dan lainlain.

Dalam lengan robot, dikenal istilah Degree of Freedom (DOF) atau derajat kebebasan. Secara umum DOF atau derajat kebebasan adalah jumlah arah yang independen yang dibutuhkan untuk menyatakan posisi dari setiap hubungan relative terhadap link yang tetap. Dalam merencanakan suatu lengan robot untuk aplikasi tertentu, perlu pertimbangan berbagai macam alternatif yang akan digunakan. Mulai pemilihan jenis penggerak, konfigurasi robot, jenis joint dan lainnya. [Siegwart, 2004].

Masalah yang muncul dari persoalan pergerakan robot adalah bagaimana robot dapat memindahkan posisinya ke lokasi yang diinginkan, dalam menyelesaikan masalah ini, dapat digunakan suatu metode yaitu kinematika maju (forward kinematics) dan kinematika balikan (inverse kinematics). Inverse Kinematics robot telah terbukti menjadi sangat penting karena solusi yang ditemukan memberikan control atas posisi dan orientasi dari lengan robot. Penelitian telah menunjukkan bahwa perhitungan kinematika maju dan kinematika balikan pada pergerakan robot dapat diselesaikan dengan menggunakan matriks aljabar (translasi-rotasi), iterative procedures atau geometric application.

Pada gerak robot diperlukan suatu metode perhitungan untuk menggerakkan dan mengkoordinasikan beberapa motor pada lengan robot agar dapat bergerak ke lokasi yang diinginkan. Tujuan utama adalah agar ujung dari lengan robot (End Point) dapat mencapai posisi 
target yang diinginkan. Dalam menyelesaikan masalah ini, dapat digunakan suatu kombinasi metode yaitu perhitungan Inverse Kinematics dan matrik Denavit-Hartenberg.

Invers kinematika adalah analisis kinematik dalam koordinasi beberapa motor penggerak untuk mendapatkan sudut dari masing - masing sendi (motor) jika diketahui koordinat posisi $(\mathrm{x}, \mathrm{y}, \mathrm{z})$ asal dan koordinat $(\mathrm{x}, \mathrm{y}, \mathrm{z})$ tujuan. Invers Kinematik mengacu pada penggunaan persamaan kinematika robot untuk menentukan nilai-nilai sudut yang memberikan posisi yang diinginkan pada posisi ujung dari lengan robot (End Point) [Spong 2005]. Dalam menghitung pergerakan robot diperlukan informasi jarak tiap-tiap lengan yang juga adalah jarak antar motor. Invers Kinematik mengubah nilai sudut menjadi sinyal yang harus diberikan kepada penggerak dalam pergerakan robot. Penelitian telah menunjukkan bahwa Inverse Kinematics robot dapat diselesaikan dengan menggunakan matriks aljabar, iterative procedures atau geometric application.

Berdasarkan penulisan yang diperoleh oleh Jacques Denavit dan Richard Hartenberg, matrik Denavit-Hartenberg adalah teknik yang paling banyak digunakan untuk menggabungkan perhitungan antara rotasi dan translasi [J. Denavit, 1955]. Pergerakan robot dari titik asal menuju titik tujuan adalah perhitungan kombinasi antara rotasi dan translasi. Pada perhitungan pergerakan robot, beberapa tahap dibentuk menggambarkan sudut rotasi. Proses ini menentukan sudut putar masing-masing sendi. Tahap lain pada gerakan adalah penggunaan matriks untuk menggambarkan pergeseran titik sendi (translasi). Oleh karena itu, setiap putaran motor dan pergeseran lengan dapat dijelaskan dalam matriks. Sehingga dari semua matriks gabungan menggambarkan posisi akhir dari lengan robot dalam suatu ruang. Matriks Denavit-Hartenberg mengkombinasikan translasi dan rotasi menjadi satu matriks 4 x 4 dengan beberapa variabel yang berisi informasi jarak motor dan sudut peletakan motor.

\section{METODE PENELITIAN}

Metode perhitungan kinematika yang digunakan adalah Denavit-Hartenberg yang diaplikasikan untuk menghitung posisi akhir pada kinematika maju atau untuk menghitung sudut tiap motor (sendi) pada kinematika balikan. Hasil dari akhir pergerakan robot akan dibandingkan dengan pengukuran manual oleh manusia untuk menghitung tingkat keakurasian dari perhitungan dan pergerakan.

Metode Danevit-Hartenberg merupakan aturan yang digunakan dalam perancangan robotika yang diperkenalkan oleh Jacques Denavit dan Ricard S. Hartenberg [J. Denavit, 1955]. Aturan tersebut menyatakan hanya terdapat dua gerakan yang mungkin terjadi yaitu bergeser dan berputar serta hanya terdapat 3 sumbu yang dapat terjadi yaitu sumbu $\mathrm{x}, \mathrm{y}$, dan $\mathrm{z}$. Notasi Denavit dan Hartenberg memberikan metodologi standar untuk menulis persamaan kinematik dari lengan robot. Hal ini khususnya berguna untuk manipulator seri di mana matriks yang digunakan untuk mewakili pose (posisi dan orientasi) dari satu tubuh terhadap yang lain.

Manipulator mekanik terdiri dari sejumlah bagian tubuh yang dinamakan link dan joint. Joint digunakan untuk menghubungkan setiap link-link yang ada. Setiap joint mewakili satu derajat kebebasan. Untuk mendeskripsikan hubungan translasional dan rotasional antara link-link yang berdekatan digunakanlah konsep Denavit dan Hartenberg sebagai sebuah metode matriks yang secara sistematis membangun sebuah sistem koordinat dari masing-masing link.

Dalam mencari sebuah transformasi dari sebuah ujung alat hingga basis dari sebuah manipulator, ditentukan frame dari link-link dan mendapatkan teknik yang sistematikal, yang dapat menjabarkan kinematika dari sebuah robot dengan derajat kebebasan dalam cara yang unik.

Matrik Denavit-Hartenberg adalah bentuk khusus dari transformasi matrik homogen [Reddy, 2014]. 


$\left[\begin{array}{l|l}\text { Rotation } & \text { Position } \\ \text { matrix }(3 \times 3) & \text { vector }(3 \times 1) \\ \hline \text { Perspective } & \text { Scaling } \\ \text { transform }(1 \times 3) & \text { factor }(1 \times 1)\end{array}\right]$

1. Matrix $(3 \times 3)$ adalah rotasi matrik

2. Vector $(3 \times 1)$ adalah posisi vector (translasi)

3. Vector $(1 \times 3)$ adalah Perspective Transform yang berisi $\{0,0,0\}$

4. Vector $(1 \times 1)$ adalah Scaling Factor yang selalu berisi nilai 1

Selain itu, transformasi matrik homogen dapat dijabarkan seperti berikut:

$$
\mathrm{T}=\left[\begin{array}{cccc}
n x & o x & a x & p x \\
n y & o y & a y & p y \\
n z & o z & a z & p z \\
0 & 0 & 0 & 1
\end{array}\right]
$$

Notasi ini mendeksripsikan parameter hubungan antara satu sendi/lengan dengan sendi/lengan yang lain. Guna memodelkan lengan robot berjenis articulated robot, digunakan notasi DenavitHartenberg. Notasi ini mendeskripsikan parameter hubungan antara satu sendi/lengan dengan sendi/lengan yang lain, terdiri dari 4 parameter (ai, ai, di, $\theta i$ ) [Reddy, 2014]. Notasi ini ditulis pada sistem koordinat XYZ.

Empat parameter ini digunakan pada transformasi matrik untuk menentukan hubungan antar matrik. Matrik ini disebut dengan Denavit-Hartenberg Matrix (D-H Matrix). Kemudian, produk dari transformasi memberikan matrik D-H [Spong 2005]:

$$
\begin{aligned}
\mathrm{A}_{(\mathrm{i}-1) \mathrm{i}}=\operatorname{Rot}(x i, \alpha i) & \operatorname{Trans}(a i, 0,0) \\
& {\left[\begin{array}{cccc}
\cos \theta i & -\cos \alpha i \sin \theta i & \sin \alpha i \sin \theta i & a i \cos \theta i \\
\sin \theta i & \cos \alpha i \cos \theta i & -\sin \alpha i \cos \theta i & \alpha i \sin \theta i \\
0 & \sin \alpha i & \cos \alpha i & d i \\
0 & 0 & 0 & 1
\end{array}\right] }
\end{aligned}
$$

Untuk n-degree of freedom manipulator, fungsi $\mathrm{P}$ adalah perkalian dari semua joint variable $\mathrm{P}=\mathrm{A}_{0 \mathrm{n}}=\mathrm{A}_{01} \times \mathrm{A}_{12} \times \mathrm{A}_{23} \times \ldots \times \mathrm{A}_{(\mathrm{n}-1) \mathrm{n}}$

Dalam model penyelesaian untuk robot yang akan dibuat dengan metode Inverse DenavitHartenberg membutuhkan parameter $\theta \mathrm{i}$, $\alpha \mathrm{i}$, di dan ai dari rancangan lengan robot. Dari tabel parameter tersebut diperolehmatrik nilai untuk tiap joint ${ }^{i-1} T_{i}$ dengan menggunakan matrik Denavit-Hartenberg [Reddy, 2014].

$$
\left[\begin{array}{cccc}
\cos \theta i & -\cos \alpha i \sin \theta i & \sin \alpha i \sin \theta i & a i \cos \theta i \\
\sin \theta i & \cos \alpha i \cos \theta i & -\sin \alpha i \cos \theta i & a i \sin \theta i \\
0 & \sin \alpha i & \cos \alpha i & d i \\
0 & 0 & 0 & 1
\end{array}\right]
$$


Dimana:

$\theta i$ adalah rotasi sumbu $z_{i}$ terhadap pergeseran sumbu $x_{i}$

di adalah jarak dari $z_{i-1}$ sampai $z_{i}$

ai adalah jarak dari $x_{i-1}$ sampai $x_{i}$

$\alpha i$ adalah perpindahan sudut terhadap sumbu $x_{i}$

\section{HASIL DAN PEMBAHASAN}

Setiap lengan robot dikaukan pengukuran menggunakan alat ukur yang umum digunakan seperti jangka sorong busur dan mistar. Setiap nilai akan dimasukkan kedalam matriks DenavitHertenberg. Sudut yang ingin dicari berada pada tiap frame (matriks) uang mengandung variabel rotasi. Invers Kinematicss pada perancangan ini adalah operasi invers matriks yang akan menghasilkan nilai-nilai rotasi yang akan dikirimkan ke tiap motor pada lengan robot.

Data yang digunakan dalam pengujian berupa data dari panjang lengan robot yang sudah hitung dari fisik lengan robot yang digunakan, jarak pergeseran sumbu robot dan tinggi dari alas robot yang sudah ditentukan sebelumnya, dan sudut untuk tiap sendi robot yang sudah disesuaikan dengan penggunaan metode Denavit-Hertenberg. Penggunaan data tersebut bertujuan untuk mencari seberapa besar persentase kesalahan yang dapat terjadi dengan membandingkan hasil dari perangkat lunak dan hasil dari perangkat keras berdasarkan data masukan yang sama. Terdapat 3 data untuk panjang lengan robot, 1 data untuk tinggi alas robot, dan 4 data untuk sudut tiap sendi robot yang secara keseluruhan akan diuji dengan 10 data masukan pengujian.Penjelasan data masukan secara rinci sebagai berikut :

1. Data panjang lengan robot

a. a2 dengan panjang $10,5 \mathrm{~cm}$ (data pengaturan awal)

b. a3 dengan panjang $7,5 \mathrm{~cm}$ (data pengaturan awal)

c. a4 dengan panjang $16 \mathrm{~cm}$ (data pengaturan awal)

2. Data tinggi alas robot

a. d1 dengan tinggi $9,1 \mathrm{~cm}$ (data pengaturan awal)

3. Data sudut sendi robot

a. $\theta 1$ berupa sudut acak dengan batasan $0^{\circ} \leq \theta 1 \leq 180^{\circ}$

b. $\theta 2$ berupa sudut acak dengan batasan $0^{\circ} \leq \theta 2 \leq 180^{\circ}$

c. $\theta 3$ berupa sudut acak dengan batasan $-90^{\circ} \leq \theta 3 \leq 90^{\circ}$

d. $\theta 4$ berupa sudut acak dengan batasan $-90^{\circ} \leq \theta 4 \leq 90^{\circ}$

Pengujian kinerja dilakukan dari input user berupa posisi koordinat benda kemudian diproses oleh sistem sehingga menghasilkan output nilai sudut yang akan dikirimkan ke perangkat Arduino uno yang kemudian menggerakkan motor servo sesuai dengan sudut yang dikirim. Hasil pengujian dapat dilihat pada tabel 1 dengan data sample 10 kali percobaan yang dilakukan.

Dari hasil pengujian yang telah dilakukan, diperoleh bahwa adanya perbedaan hasil antara perangkat lunak dan perangkat keras dengan tingkat kesalahan rata-rata untuk posisi $\mathrm{x}(\mathrm{px})$ sebesar 96.8\%, tingkat kesalahan rata-rata untuk posisi y (py) sebesar $61.14 \%$, dan tingkat kesalahan rata-rata untuk posisi z (pz) sebesar 9.64\%.

Perbedaan posisi antara aplikasi dengan posisi yang dicapai end point terjadi karena kurang tepatnya nilai kalibrasi dan properti ukuran dari lengan robot. Hal ini mengakibatkan nilai tersebut terbawa dalam perhitungan dan dapat semakin meningkat (Dead-Reckoning). Kesalahan yang terjadi masih dapat ditolelir ketika sistem digunakan untuk memindahkan kaca preparat. 
Hal ini disebabkan selisih jarak antara perhitungan sistem dan pergerakan lengan robot masih dalam satuan milimeter.

Tabel 1 Hasil Pengujian Kinematika Balikan

\begin{tabular}{|c|c|c|c|c|c|c|c|}
\hline \multirow{2}{*}{ Sample } & \multicolumn{3}{|c|}{ Koordinat Benda } & \multicolumn{4}{|c|}{ Sudut } \\
\hline & $\mathbf{X}$ & $\mathbf{Y}$ & $\mathbf{Z}$ & $\theta 1$ & $\theta 2$ & $\theta 3$ & $\theta 4$ \\
\hline 1 & 26.5 & 7.1 & 23.6 & $15^{\circ}$ & $54.26^{\circ}$ & $0^{\circ}$ & $-54.26^{\circ}$ \\
\hline 2 & 10 & 30 & 15 & $71.57^{\circ}$ & $17.47^{\circ}$ & $60^{\circ}$ & $-77.47^{\circ}$ \\
\hline 3 & 18 & 25 & 20 & $54.25^{\circ}$ & $36.1^{\circ}$ & $25.84^{\circ}$ & $-61.94^{\circ}$ \\
\hline 4 & 29.84 & 0 & 20.84 & $0^{\circ}$ & $40.25^{\circ}$ & $25.84^{\circ}$ & $-66.09^{\circ}$ \\
\hline 5 & 26.44 & 15.3 & 19.6 & $30.06^{\circ}$ & $34.74^{\circ}$ & $36.87^{\circ}$ & $-71.61^{\circ}$ \\
\hline 6 & 32.32 & 0 & 17.72 & $0^{\circ}$ & $27.17^{\circ}$ & $25.84^{\circ}$ & $-53.02^{\circ}$ \\
\hline 7 & 27 & 0 & 24 & $0^{\circ}$ & $56.13^{\circ}$ & $0^{\circ}$ & $-56.13^{\circ}$ \\
\hline 8 & 29.5 & 0 & 20 & $0^{\circ}$ & $37.44^{\circ}$ & $45.57^{\circ}$ & $-83.01^{\circ}$ \\
\hline 9 & 16 & 28 & 18 & $60.26^{\circ}$ & $28.08^{\circ}$ & $25.84^{\circ}$ & $-53.92^{\circ}$ \\
\hline 10 & 19 & 27.77 & 10.56 & $55.62^{\circ}$ & $1.36^{\circ}$ & $45.57^{\circ}$ & $-46.94^{\circ}$ \\
\hline
\end{tabular}

Referensi: Hasil pengujian pada pergerakan lengan robot, 2016

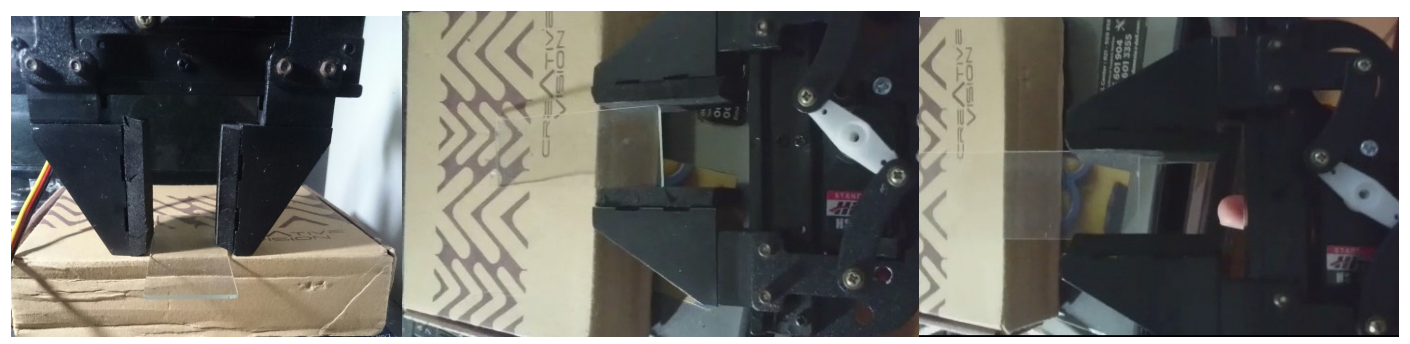

Gambar 1 Uji Pengambilan Objek

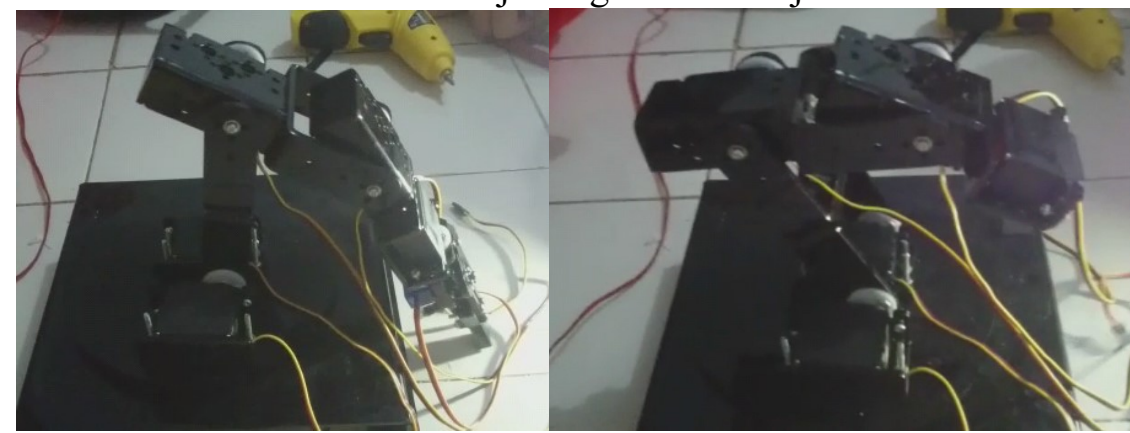

Gambar 2 Uji pergerakan Lengan Robot

\section{KESIMPULAN DAN SARAN}

Metode Denavit-Hartenberg dapat digunakan sebagai perhitungan Invers Kinematicss untuk mencari besar dari nilai sudut tiap joint yang diperlukan untuk mencapai posisi yang diinginkan. Pencarian posisi dari ujung lengan sebuah robot manipulator menjadi lebih mudah dan cepat serta efisien dengan menggunakan aplikasi yang menggunakan metode Invers Kinematicss Denavit-Hartenberg. Dengan metoda ini, perhitungan aljabar dan geometri pada invers dapat diolah dengan baik dalam perhitungan matriks yang berisi matrik rotasi dan translasi. Aplikasi 
dapat menghasilkan gerakan yang baik jika dilakukan kalibrasi sehingga menghasilkan nilai error rotasi motor yang lebih sedikit. Metode invers calibration (Kalibrasi Mundur) juga dapat diterapkan guna mendapatkan nilai penjang lengan berdasarkan hasil proses forward kinematics.

\section{Ucapan Terima Kasih (Acknowledgement)}

Ucapan terima kasih kepada Direktorat Penelitian dan Pengabdian kepada Masyarakat Universitas Tarumanagara yang telah memberikan kontribusi yang bermakna bagi penelitian dan publikasi ini.

\section{REFERENSI}

Craig, J., (2005). Introduction to Robotics: Mechanics and Control (3rd Edition). Pearson Education International.

J.Denavit, R.S.Hartenberg, A kinematic notation for lower-pair mechanisms based on matrices, Transactions ASME Journal of Applied Mechanics, 1955

Kay, J. (2005). Introduction to Homogeneous Transformations \& Robot Kinematicss. Rowan University Computer Science Department.

Kendricks, K,. (2007). Solving the Inverse Kinematic Robotics Problem, Auburn University.

Kucuk, S., \& Zafer B. (2016). Robot Kinematics :Forward and Invers Kinematicss. Industrial Robotics: Theory, Modelling and Control.

Reddy, A. C., (2014). Difference Between Denavit-Hartenberg (D-H) Classical and Modified Conventions for Forward Kinematics of Robot with Case Study, AMMT.

Schmitt, M., Liss, P., Schmidt,S.,; Hackenberger, B., (März 2010). Project Report, Kinematics Software Library. Hochschule Darmstadt.

Siegwart, Roland. (2004). Introduction to autonomous mobile robots. A Bradford Book The MIT Press Cambridge, Massachusetts London, England

Singh, P., et al. (2013). Forward Kinematics analysis of 6 DOF Robotic Manipulator.International Journal of Mechanical Science and Civil Engineering IJMSCE Special issue on "Emerging Trends in Engineering \& Management" ICETE

Spong, M. W., Hutchinson, S., Vidyasagar M., (2005) Robot Modeling and Control, ISBN-10: 0471649902, ISBN-13: 978-0471649908, Edition: 1

Zimmermann, S. (2010). Design und Implementierung einer Systemplattform für ein aktives Kameranetzwerk. Master-Thesis. Hochschule Darmstadt. 